\title{
A tendência do valor aluno/ano do Fundeb e o CAQi: algumas observações
}

\author{
The trend of Fundeb national student/year minimum value \\ and the CAQi:
}

some observations

\author{
La tendencia del valor mínimo nacional por alumno/año del Fundeb \\ y el CAQi: \\ algunas observaciones
}

\author{
RUBENS BARBOSA DE CAMARGO* \\ Universidade de São Paulo, São Paulo- SP, Brasil.
}

\author{
ANA PAULA SANTIAGO DO NASCIMENTO** \\ Universidade Federal de São Paulo, São Paulo- SP, Brasil.
}

\section{RENATA RODRIGUES DE AMORIM MEDINA*** \\ Secretaria Estadual de Educação de São Paulo, São Paulo- SP, Brasil.}

\begin{abstract}
RESUMO: Em função da condição do término do prazo de vigência do Fundeb em 2020 é necessário que sejam realizadas análises acerca de seus efeitos sobre o financiamento da educação básica no Brasil e de cada um de seus fundos. Tendo isso em mente, este artigo pretende ser mais uma contribuição para este debate, organizando e apresentando dados e análises específicas sobre os montantes totais do Fundeb, os valores mínimos nacionais e máximos existentes entre os fundos no período de 2007 a 2018 e os valores do CAQi de alguns anos, apresentados em diferentes anos pela Campanha Nacional pelo Direito à Educação.
\end{abstract}

\footnotetext{
* Professor Assistente I do Departamento de Administração Escolar e Economia da Educação da Faculdade de Educação da Universidade de São Paulo. E-mail: <rubensbc@usp.br>.

** Professora de Educação Básica Técnica e Tecnológica do Núcleo de Educação Infantil -Escola de Educação da UNIFESP. E-mail:<anpaula@usp.br>.

*** Professora da rede estadual de São Paulo. E-mail: <re.ramedina@gmail.com>.
} 
Palavras-chave: FUNDEB; PNE; CAQi; CAQ; Financiamento da Educação.

\begin{abstract}
Due to the condition that Fundeb will expire in 2020, it is necessary to carry analyzes on its effects on the financing of basic education in Brazil and each of its funds. With this in mind, this article is intended to be a further contribution to this debate by organizing and presenting specific data and analysis on the total Fund for Basic Education and for Enhancing the Value of the Teaching Profession (Fundeb) amounts, the national minimum and maximum values between the funds in the period 2007-2018 and the values of the Cost of Initial Quality Education per Student (CAQi) of some years, presented in different years by the National Campaign for the Right to Education.

Keywords: FUNDEB; PNE; CAQi; CAQ; Education Financing.
\end{abstract}

RESUMEN: Debido a la condición de que Fundeb expire en 2020, se requiere un análisis de sus efectos sobre el financiamiento de la educación básica en Brasil y cada uno de sus fondos. Con esto en mente, este artículo pretende ser una contribución adicional a este debate, mediante la organización y presentación de datos y análisis específicos sobre los montos totales de Fundeb, los valores mínimos nacionales y máximos existentes entre los fondos en el período 2007 a 2018 y los valores del CAQi de algunos años, presentados en distintos años por la Campaña Nacional por el Derecho a la Educación.

Palabras clave: FUNDEB; PNE; CAQi; CAQ; Financiamiento de la Educación.

\title{
Introdução
}

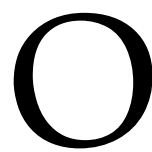

Fundo de Manutenção e Desenvolvimento da Educação Básica e de Valorização dos Profissionais da Educação (Fundeb), criado pela Emenda Constitucional

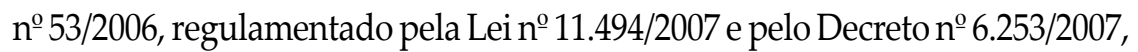
para substituir o Fundo de Manutenção e Desenvolvimento do Ensino Fundamental e de Valorização do Magistério (Fundef), com vigência estipulada para o período de 20072020, completou 12 anos e caminha para o prazo previsto para o seu fim.

A ideia de uma política de fundos é a de subvincular parte das receitas líquidas de impostos e transferências que compõem as vinculações constitucionais e que já são 
destinadas como receitas de Manutenção e Desenvolvimento do Ensino (MDE) pela Constituição Federal de 1988 (CF/88), para constituir fundos estaduais específicos, que teriam a incumbência de redistribuir os recursos financeiros arrecadados em cada território correspondente ao estado (envolvendo todos os municípios e a esfera estadual nele presentes), a partir do número de matrículas em cada etapa ou modalidade do ensino. Com esta intenção, foram criados, a partir de 2010, 27 fundos $^{1}$ (incluindo o Distrito Federal), com a União cumprindo papel redistributivo e suplementar equivalente a $10 \%$ da somatória dos montantes dos fundos do País.

Em função do término do prazo de validade do Fundeb, é necessário realizar análises sobre seus efeitos sobre o financiamento da educação básica no Brasil e de cada um de seus fundos. O debate é necessário não só do ponto de vista acadêmico, mas em função de análises e proposições de uma nova legislação sobre o Fundeb no Congresso Nacional.

Uma das questões que se coloca neste debate está ligada à discussão sobre sua capacidade de contribuir para a expansão do atendimento em todas as etapas e modalidades da educação básica e se conseguiu incidir na diminuição das diferenças de aplicação de recursos educacionais num mesmo território e das diferenças entre os estados brasileiros.

Além dessa discussão, entra em cena, no quinto ano do Plano Nacional de Educação (PNE) - ano em que o Brasil deveria investir algo em torno de 7\% do PIB em educação e, também, em que o País deveria ter formulado de modo claro a forma de cálculo nacional e implantado o Custo Aluno-Qualidade Inicial (CAQi), bem como implantar o Custo Aluno-Qualidade (CAQ), como previsto nas estratégias 20.6, 20.7 e 20.8 do PNE, o que, como todos sabem, não foi feito...

Este artigo pretende ser mais uma contribuição para o debate, organizando e apresentando dados e análises específicas sobre os montantes totais do Fundeb, os valores mínimos e máximos entre os fundos, no período de 2007 a 2018, e os valores do CAQi, em diferentes anos, sustentados pela Campanha Nacional pelo Direito à Educação.

\section{Montantes do Fundeb no período de 2007 a 2018}

A análise dos montantes destinados aos fundosno site do Fundo Nacional de Desenvolvimento da Educação (FNDE) permite perceber que eles sempre cresceram nominalmente, saindo de $\mathrm{R} \$ 48,1$ bilhões, em 2007, para $\mathrm{R} \$ 156,4$ bilhões, em 2019, representando uma diferença de 225\%, entre 2007 e 2019. As contribuições da União aos fundos também sempre foram crescentes, como determinava a Lei, passando de $\mathrm{R} \$ 2$ bilhões, em 2007, para R\$14,3 bilhões, em 2019.

No entanto, a melhor forma de analisar a situação é verificar como se comportaram esses valores, quando corrigidos pelos índices inflacionários, para melhor apreciaresses montantes. Foi o que foi feito no Gráfico 01, onde se apresenta os montantes destinados ao 
Fundeb, de 2007 a 2019, corrigidos pelo Índice Nacional de Preços ao Consumidor (INPC) de dezembro de 2018. Nele estão registradas as curvas do Valor Fundeb Brasil (onde se apresentam os valores totais do Fundo, isto é, a somatória de todos os fundos dos estados adicionada ao valor de complementação da União); o valor da somatória dos fundos de todos os estados, municípios e DF; e o valor separado da complementação da União.

\section{Gráfico 1 - Montantes Fundeb Brasil Total, montantes do Fundeb dos estados e DF, contribuição da União (2007-2019). Valores corrigidos em mil R\$ (dez 2018 - INPC)}

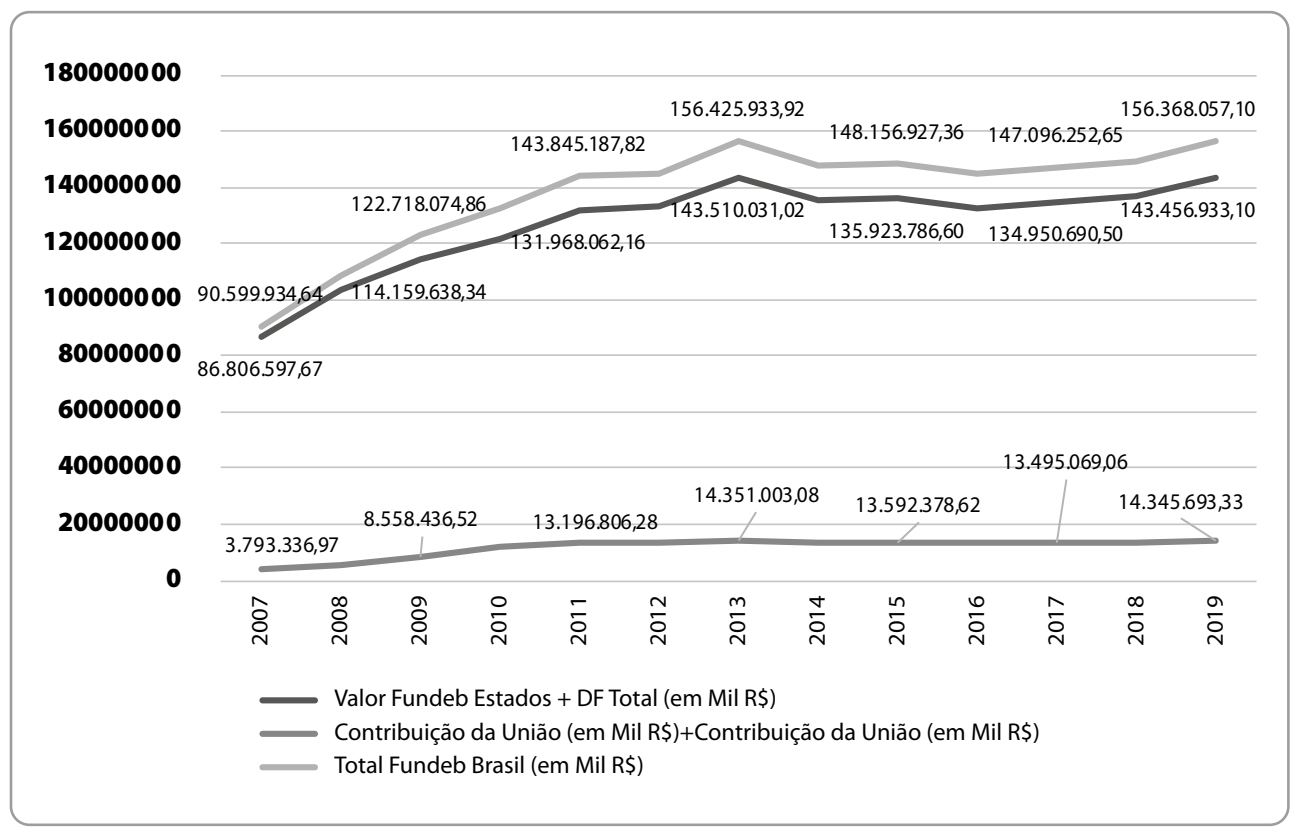

Fonte: Autores, com base em dados do FNDE (2007-2019).

No gráfico 01, pode-se observar que os montantes corrigidos e discriminados oscilam, mas as curvas mantêm uma tendência de crescimento.

Ao se analisar o comportamento dos montantes do Valor Total Fundeb Brasil e do Valor Total Fundeb dos estados e DF, percebe-se que a curva é muito parecida, tanto nas oscilações, quanto nos picos de maior valor, em 2013, quando foram R $\$ 156,4$ bilhões e $\mathrm{R} \$ 143,5$ bilhões, respectivamente. O Valor Total Fundeb Brasil inicia o período (em 2007) com $\mathrm{R} \$ 90,6$ bilhões e termina com $\mathrm{R} \$ 156,4$ bilhões (em 2019), revelando um crescimento real de $73 \%$, enquanto que o Valor Total Fundeb estados e DF apresenta um crescimento real de 65\%, passando de R \$ 86,8 bilhões, em 2007, para R \$ 143,5 bilhões ,em 2019.

Observa-se que a Contribuição da União foi um pouco mais estável após 2011, mas iniciou o período com $\mathrm{R} \$ 3,8$ bilhões em 2007, apresentou seu maior valor em 2013, na ordem dos $\mathrm{R} \$ 14,4$ bilhões, e findou a série com $\mathrm{R} \$ 14,3$ bilhões em 2019, totalizando um 
crescimento real de $278 \%$. Foi quem registrou o maior crescimento percentual no período do estudo. O que mostra a capacidade da União em colocar recursos como complementação aos fundos em cada estado que não atingiu o valor mínimo nacional.

\section{Valor Aluno-Ano Mínimo Nacional e Valor Aluno-Ano Máximo Registrado}

Uma forma de detectar se o valor aluno-ano do Fundeb teve uma distribuição mais equitativa entre as formas de atendimento dos alunos da educação básica no decorrer do período é realizar a análise dos valores aluno-ano mínimo nacional do Fundeb por etapa de ensino. Lembrando que no decorrer dos anos de existência do Fundo alguns destes valores passaram por ajustes em seus fatores de ponderação no período. A Tabela 01, a seguir, apresenta os valores aluno-ano mínimos nacionais, para cada etapa e algumas modalidades, nos anos de 2007 a 2019, e apresenta a diferença desses valores no período.

Tabela 1 - Valores aluno-ano mínimos nacionais (2007-2009). Em R\$ corrigidos (dez 2018 - INPC)

\begin{tabular}{|c|c|c|c|c|c|c|c|}
\hline Anos & $\begin{array}{c}\text { Valor } \\
\text { Mínimo } \\
\text { Nacional } \\
\text { CRECHE } \\
\text { INTEGRAL } \\
\text { (em R\$) }\end{array}$ & $\begin{array}{c}\text { Valor } \\
\text { Mínimo } \\
\text { Nacional } \\
\text { PRÉ } \\
\text { ESCOLA } \\
\text { PARCIAL } \\
\text { (em R\$) }\end{array}$ & $\begin{array}{c}\text { Valor } \\
\text { Mínimo } \\
\text { Nacional } \\
\text { Ensino } \\
\text { Fundamental } \\
\text { Urbano } \\
\text { Séries } \\
\text { Iniciais (em } \\
\text { R\$) }\end{array}$ & $\begin{array}{c}\text { Valor } \\
\text { Mínimo } \\
\text { Nacional } \\
\text { Ensino } \\
\text { Fundamental } \\
\text { Urbano } \\
\text { Séries Finais } \\
\text { (em R\$) }\end{array}$ & $\begin{array}{c}\text { Valor } \\
\text { Mínimo } \\
\text { Nacional } \\
\text { Ensino } \\
\text { Médio } \\
\text { Urbano } \\
\text { (em R\$) }\end{array}$ & $\begin{array}{c}\text { Valor } \\
\text { Mínimo } \\
\text { Nacional } \\
\text { Educação } \\
\text { Especial } \\
\text { (em R\$) }\end{array}$ & $\begin{array}{c}\text { Valor } \\
\text { Mínimo } \\
\text { Nacional } \\
\text { EJA (em } \\
\text { R\$) }\end{array}$ \\
\hline 2007 & 1428,42 & 1606,98 & 1785,53 & 1964,08 & 2142,64 & 2142,64 & 1249,87 \\
\hline 2008 & 2190,13 & 1791,92 & 1991,02 & 2190,13 & 2389,23 & 2389,23 & 1393,72 \\
\hline 2009 & 2267,78 & 2061,63 & 2061,63 & 2267,78 & 2473,94 & 2473,94 & 1649,30 \\
\hline 2010 & 2476,42 & 2251,30 & 2251,30 & 2476,42 & 2701,56 & 2701,56 & 1801,04 \\
\hline 2011 & 3109,90 & 2591,59 & 2591,59 & 2850,74 & 3109,90 & 3109,90 & 2073,27 \\
\hline 2012 & 3433,22 & 2640,93 & 2640,93 & 2905,03 & 3169,12 & 3169,12 & 2112,75 \\
\hline 2013 & 3869,16 & 2976,27 & 2976,27 & 3273,90 & 3571,53 & 3571,53 & 2381,01 \\
\hline 2014 & 3743,24 & 2879,42 & 2879,42 & 3167,36 & 3599,27 & 3455,30 & 2303,53 \\
\hline 2015 & 3756,64 & 2889,72 & 2889,72 & 3178,69 & 3612,15 & 3467,66 & 2311,78 \\
\hline 2016 & 3765,42 & 2896,48 & 2896,48 & 3186,13 & 3620,59 & 3475,77 & 2317,18 \\
\hline 2017 & 3945,41 & 3034,93 & 3034,93 & 3338,41 & 3793,66 & 3641,91 & 2427,94 \\
\hline 2018 & 3963,35 & 3048,73 & 3048,73 & 3353,60 & 3810,91 & 3658,48 & 2438,99 \\
\hline 2019 & 4210,08 & 3400,45 & 3238,52 & 3562,37 & 4048,15 & 3886,23 & 2590,82 \\
\hline
\end{tabular}




\begin{tabular}{|c|c|c|c|c|c|c|c|}
\hline Anos & $\begin{array}{c}\text { Valor } \\
\text { Mínimo } \\
\text { Nacional } \\
\text { CRECHE } \\
\text { INTEGRAL } \\
\text { (em R\$) }\end{array}$ & $\begin{array}{c}\text { Valor } \\
\text { Mínimo } \\
\text { Nacional } \\
\text { PRÉ } \\
\text { ESCOLA } \\
\text { PARCIAL } \\
\text { (em R\$) }\end{array}$ & $\begin{array}{c}\text { Valor } \\
\text { Mínimo } \\
\text { Nacional } \\
\text { Ensino } \\
\text { Fundamental } \\
\text { Urbano } \\
\text { Séries } \\
\text { Iniciais (em } \\
\text { R\$) }\end{array}$ & $\begin{array}{c}\text { Valor } \\
\text { Mínimo } \\
\text { Nacional } \\
\text { Ensino } \\
\text { Fundamental } \\
\text { Urbano } \\
\text { Séries Finais } \\
\text { (em R\$) }\end{array}$ & $\begin{array}{c}\text { Valor } \\
\text { Mínimo } \\
\text { Nacional } \\
\text { Ensino } \\
\text { Médio } \\
\text { Urbano } \\
\text { (em R\$) }\end{array}$ & $\begin{array}{c}\text { Valor } \\
\text { Mínimo } \\
\text { Nacional } \\
\text { Educação } \\
\text { Especial } \\
\text { (em R\$) }\end{array}$ & $\begin{array}{c}\text { Valor } \\
\text { Mínimo } \\
\text { Nacional } \\
\text { EJA (em } \\
\text { R\$) }\end{array}$ \\
\hline $\begin{array}{l}\text { Dif. } \\
2019- \\
2007\end{array}$ & 2781,66 & 1793,47 & 1452,99 & 1598,29 & 1905,51 & 1743,59 & 1340,95 \\
\hline $\begin{array}{c}\text { Dif. } \\
2019- \\
2007 \\
\%\end{array}$ & $195 \%$ & $112 \%$ & $81 \%$ & $81 \%$ & $89 \%$ & $81 \%$ & $107 \%$ \\
\hline
\end{tabular}

Fonte: Autores, com dados do FNDE.

Na tabela 01, é possível verificar que todos os valores aluno-ano mínimo nacionais, após a correção da inflação (pelo INPC), tiveram aumentos percentuais no período de mais de $80 \%$, sendo o valor aluno-ano mínimo nacional do ensino fundamental (anos iniciais e finais urbano) e o da educação especial a etapa ou modalidade que tiveram os menores aumentos percentuais (81\%), enquanto os valores aluno-ano mínimo nacional de creche integral tiveram o maior crescimento percentual no período (195\%), saindo de $\mathrm{R} \$ 1.428,42$, em 2007, para $\mathrm{R} \$ 4.210,08$, em 2019, uma diferença de $\mathrm{R} \$ 2.781,66$.

Quando analisamos os valores máximos entre os valores aluno-ano nos estados (que podem variar em cada ano, pois este valor depende dos montantes arrecadados na cesta de impostos e do número de matrículas no ano anterior), percebe-se que as variações no período foram menores, com crescimento entre $16 \%$ (ensino fundamental - anos iniciais urbanos) e 106\% (creche integral). A Tabela 2, a seguir, traz os valores máximos do Fundeb por ano. por etapa e modalidade da educação básica, encontrados em alguns estados, para os anos de 2007 a 2019 e as diferenças no período.

\section{Tabela 2 - Valores aluno máximos em cada ano registrados nos estados}

\begin{tabular}{|c|c|c|c|c|c|c|c|}
\hline Anos & $\begin{array}{c}\text { Valor } \\
\text { Máximo } \\
\text { Nacional } \\
\text { CRECHE } \\
\text { INTEGRAL } \\
\text { (em R\$) RR }\end{array}$ & $\begin{array}{c}\text { Valor } \\
\text { Máximo } \\
\text { Nacional } \\
\text { PRÉ } \\
\text { ESCOLA } \\
\text { (em RS) }\end{array}$ & $\begin{array}{c}\text { Valor } \\
\text { Máximo } \\
\text { Nacional } \\
\text { Ensino } \\
\text { Fundamental } \\
\text { Urbano } \\
\text { Séries } \\
\text { Iniciais (em } \\
\text { R\$) }\end{array}$ & $\begin{array}{c}\text { Valor } \\
\text { Máximo } \\
\text { Nacional } \\
\text { Ensino } \\
\text { Fundamental } \\
\text { Urbano } \\
\text { Séries Finais } \\
\text { (em R\$) }\end{array}$ & $\begin{array}{c}\text { Valor } \\
\text { Máximo } \\
\text { Nacional } \\
\text { Ensino } \\
\text { Médio } \\
\text { Urbano } \\
\text { (em R\$) }\end{array}$ & $\begin{array}{c}\text { Valor } \\
\text { Máximo } \\
\text { Nacional } \\
\text { Educação } \\
\text { Especial } \\
\text { (em R\$) }\end{array}$ & $\begin{array}{c}\text { Valor } \\
\text { Máximo } \\
\text { Nacional } \\
\text { EJA (em } \\
\text { R\$) }\end{array}$ \\
\hline 2007 & 3088,35 & 3474,40 & 4227,18 & 4474,02 & 4632,51 & 4632,51 & 2702,31 \\
\hline
\end{tabular}




\begin{tabular}{|c|c|c|c|c|c|c|c|}
\hline Anos & $\begin{array}{c}\text { Valor } \\
\text { Máximo } \\
\text { Nacional } \\
\text { CRECHE } \\
\text { INTEGRAL } \\
\text { (em R\$) RR }\end{array}$ & $\begin{array}{c}\text { Valor } \\
\text { Máximo } \\
\text { Nacional } \\
\text { PRÉ } \\
\text { ESCOLA } \\
\text { (em R\$) }\end{array}$ & $\begin{array}{c}\text { Valor } \\
\text { Máximo } \\
\text { Nacional } \\
\text { Ensino } \\
\text { Fundamental } \\
\text { Urbano } \\
\text { Séries } \\
\text { Iniciais (em } \\
\text { R\$) }\end{array}$ & $\begin{array}{c}\text { Valor } \\
\text { Máximo } \\
\text { Nacional } \\
\text { Ensino } \\
\text { Fundamental } \\
\text { Urbano } \\
\text { Séries Finais } \\
\text { (em R\$) }\end{array}$ & $\begin{array}{c}\text { Valor } \\
\text { Máximo } \\
\text { Nacional } \\
\text { Ensino } \\
\text { Médio } \\
\text { Urbano } \\
\text { (em R\$) }\end{array}$ & $\begin{array}{c}\text { Valor } \\
\text { Máximo } \\
\text { Nacional } \\
\text { Educação } \\
\text { Especial } \\
\text { (em R\$) }\end{array}$ & $\begin{array}{c}\text { Valor } \\
\text { Máximo } \\
\text { Naciona } \\
\text { EJA (em } \\
\text { R\$) }\end{array}$ \\
\hline 2008 & 4968,93 & 4065,49 & 4517,22 & 4968,93 & 5420,66 & 5420,66 & 3162,04 \\
\hline 2009 & 4379,53 & 3981,40 & 4222,26 & 4479,81 & 4777,66 & 4777,66 & 3185,11 \\
\hline 2010 & 4664,53 & 4240,48 & 4240,48 & 4664,53 & 5088,59 & 5088,59 & 3392,39 \\
\hline 2011 & 5243,07 & 4369,22 & 4369,22 & 4806,15 & 5243,07 & 5243,07 & 3495,38 \\
\hline 2012 & 5494,34 & 4226,41 & 4226,41 & 4649,06 & 5071,70 & 5071,70 & 3381,13 \\
\hline 2013 & 6361,23 & 4893,26 & 4893,26 & 5382,58 & 5871,90 & 5871,90 & 3914,60 \\
\hline 2014 & 6431,80 & 4947,53 & 4947,53 & 5442,28 & 6184,42 & 5937,04 & 3958,03 \\
\hline 2015 & 6036,44 & 4643,41 & 4643,41 & 5107,75 & 5804,27 & 5572,10 & 3714,73 \\
\hline 2016 & 6520,06 & 5015,43 & 5015,43 & 5516,97 & 6269,28 & 6018,51 & 4012,35 \\
\hline 2017 & 6183,35 & 4756,43 & 4756,43 & 5232,07 & 5945,53 & 5707,71 & 3805,14 \\
\hline 2018 & 6119,39 & 4707,22 & 4707,22 & 5177,94 & 5884,03 & 5648,67 & 3765,78 \\
\hline 2019 & 6355,67 & 5133,42 & 4888,97 & 5377,87 & 6111,22 & 5866,77 & 3911,18 \\
\hline $\begin{array}{l}\text { Dif. } \\
2019- \\
2007\end{array}$ & 3267,32 & 1659,02 & 661,79 & 903,85 & 1478,71 & 1234,26 & 1208,87 \\
\hline $\begin{array}{c}\text { Dif. } \\
2019- \\
2007 \\
\%\end{array}$ & $106 \%$ & $48 \%$ & $16 \%$ & $20 \%$ & $32 \%$ & $27 \%$ & $45 \%$ \\
\hline
\end{tabular}

Fonte: Autores, com base nos dados do FNDE.

O valor máximo do valor aluno-ano matriculado na creche integral passa de $\mathrm{R} \$$ 3.088,35, em 2007, e atinge $\mathrm{R} \$ 6.355,67$, em 2019, uma diferença de $\mathrm{R} \$ 3.267,32$ (106\%) em doze anos de fundo. O maior valor máximo foi atingido em $2014(\mathrm{R} \$ 6.431,80)$ e o menor, em 2007 (R $\$ 3.088,35)$.

O valor máximo do valor aluno-ano dos anos iniciais do ensino fundamental urbano teve menor oscilação, pois saiu de $\mathrm{R} \$$ 4.227,18 em 2007 (menor valor máximo) e chega em $\mathrm{R} \$ 4.888,97$ em 2019, uma diferença de $\mathrm{R} \$ 661,79$ (16\%). O maior valor atingido por essa etapa da educação básica foi em 2016, com R \$ 5.015,43.

Quando se analisa os gráficos 2 e 3 abaixo, onde estão apresentados os valores máximos e mínimos anuais dos alunos atendidos na creche integral e nos anos iniciais do 
ensino fundamental urbano, pode-se perceber que há uma diferença entre os valores máximos e mínimos, uma tendência de crescimento em ambos, mas com crescimentos bem distintos.

\section{Gráfico 2 - Valor Aluno-Ano Fundeb - Creche Integral (2007-2019) valores corrigidos dez INPC em R\$ - 2018}

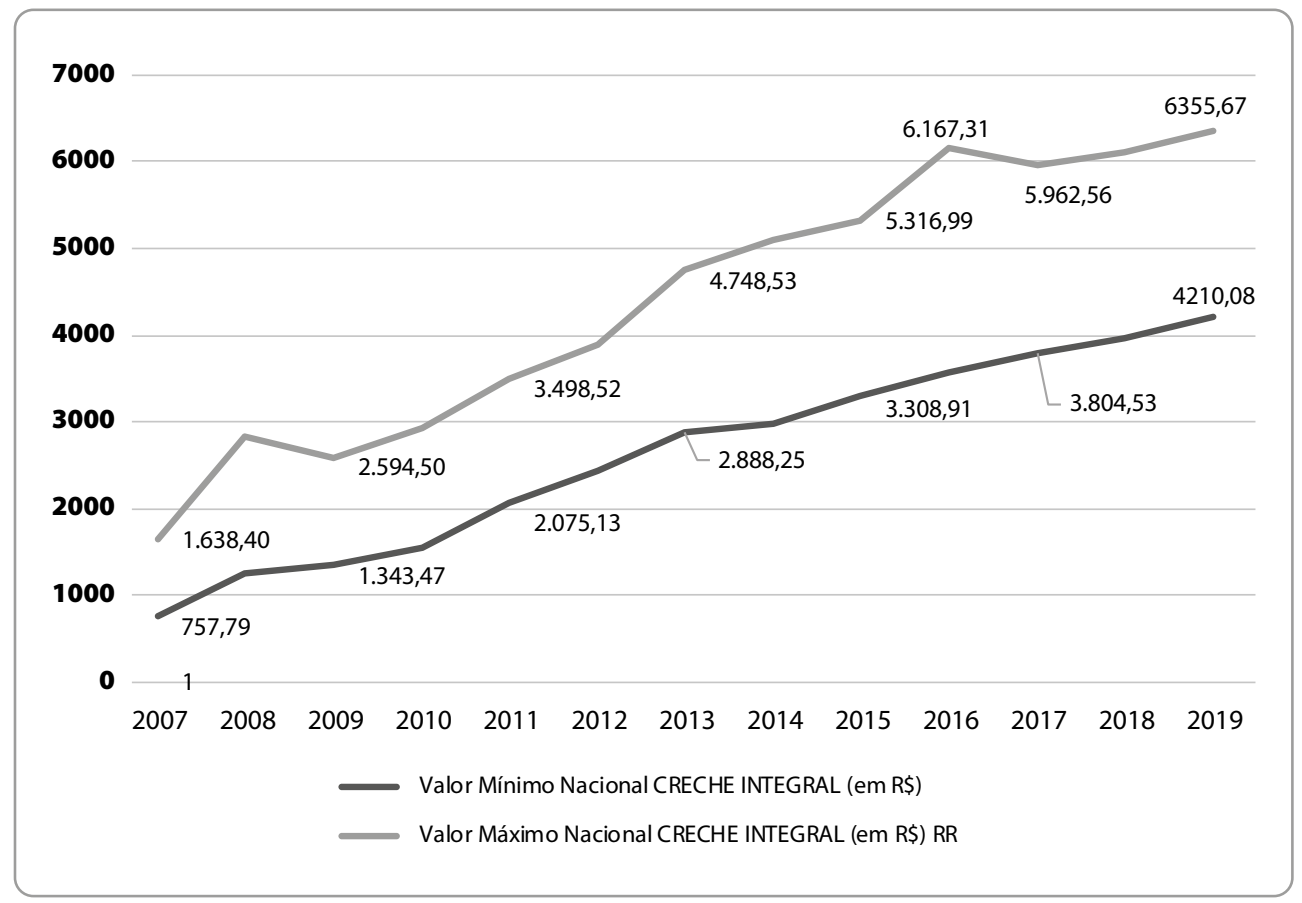

Fonte: Autores, com base nos dados do FNDE.

Pode-se observar que os valores máximos e mínimos do valor aluno-ano da creche, em período integral entre 2007 a 2019, também têm diferenças entre si: ambos crescem no período, porém de forma bastante distintas. Os valores mínimos tiveram o menor valor em 2007 ( $R$ \$ 1.428,42) e o maior valor em 2019 ( $R$ \$ 4.210,08), com uma diferença de $\mathrm{R} \$ 2.781,66$ (195\%) entre eles. Entre os valores máximos, o menor ocorreu em 2007 (R\$ $3.088,35$ ) e atinge $R \$ 6.355,67$ em 2019, estabelecendo uma diferença de $R \$ 3.267,32$ entre estes (106\%). O maior valor ocorreu em 2016, com $\mathrm{R} \$ 6.520,06$.

A maior diferença absoluta entre os valores máximos e mínimos do valor aluno-ano da creche em período integral foi de $\mathrm{R} \$ 2.778,80$ (127\%) em 2008, e a menor diferença entre máximo e mínimo foi de $\mathrm{R}$ \$1.659,93 (116\%) em 2007, ano da instalação do Fundeb e onde a creche teve o menor fator de ponderação. A menor diferença percentual entre máximo e mínimo ocorreu em 2019, com 51\%; com isso, é possível perceber uma tendência de diminuição das diferenças no período de 2007 a 2019. 


\section{Gráfico 3 - Valor Aluno-Ano Fundeb - Anos iniciais ensino fundamental urbano (2007-2019) valores corrigidos dez INPC em R\$ - 2018}

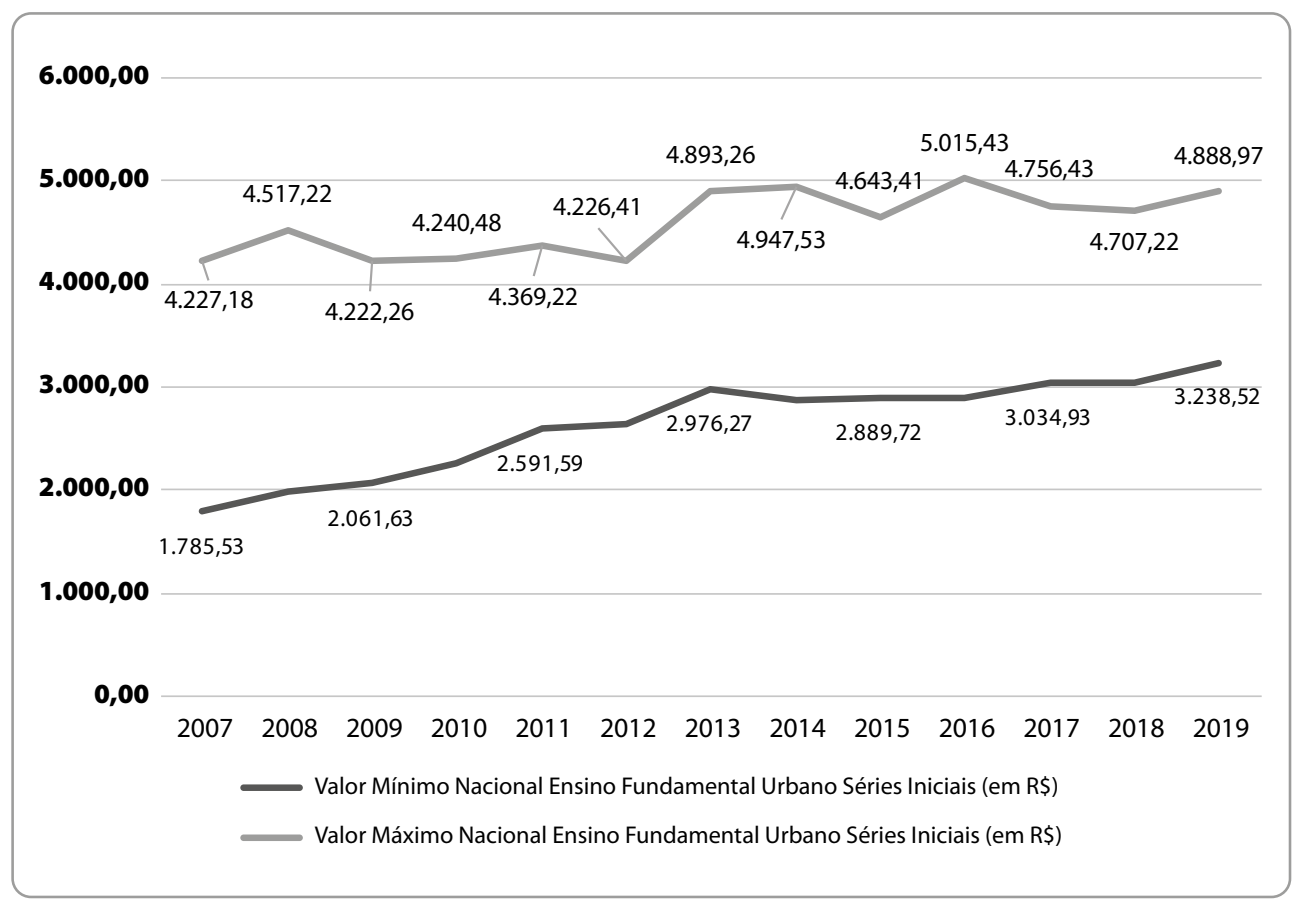

Fonte: Autores, com base nos dados do FNDE.

Analisando os valores mínimos do valor aluno-ano dos anos iniciais do ensino fundamental urbano no gráfico 03 , percebe-se que o menor valor entre os valores mínimos ocorreu em 2007, com R \$1.785,53, e o maior valor mínimo nacional é o de 2019, com R\$ 3.238,52. Uma diferença de $\mathrm{R} \$ 1.452,99$ (81\%).

A análise dos valores máximos do valor aluno-ano dos anos iniciais do ensino fundamental urbano permite perceber que houve certa oscilação, com o menor valor aparecendo em 2009 ( $\mathrm{R} \$ 4.222,26$ ) e o maior valor em 2016 ( $\mathrm{R} \$ 5.015,43)$, uma diferença de $\mathrm{R} \$ 661,79$ (16\%) entre esses dois valores. Pode-se, ainda, observar que com o passar dos anos os valores mínimos nacionais se aproximaram dos valores máximos, indicando uma tendência de maior igualdade entre esses valores nos diferentes fundos estaduais.

Para perceber melhor tal fenômeno, elaborou-se os gráficos 4 e 5 onde são apresentadas as diferenças percentuais entre os valores máximos e mínimos do valor aluno-ano de creche em tempo integral e dos anos iniciais do ensino fundamental urbano. Os dados revelam essa diminuição das diferenças percentuais entre os valores. 
Gráfico 4 - Diferença percentual dos valores máximos e mínimos de Creche integral (corrigidos dez 2018)



Fonte: Autores, com base nos dados FNDE.

A análise do gráfico 4, relativo à diferença percentual entre valor máximo e mínimo do valor aluno-ano da creche integral, permite que se perceba que ela passa de $116 \%$ em 2007, cresce para 127\% em 2008 (maior diferença) e vai diminuindo de modo oscilante até atingir 51\% em 2019.

No mesmo gráfico é apresentada uma reta como a linha de tendência com a expressão:

$$
y=-0,0521 x+1,123
$$

Tal equação indica que, mantida a tendência de estabelecimento dos valores máximos e mínimos para a creche em período integral, a partir de 2007 levar-se-ia 21,5 anos para que a diferença entre estes valores fosse igual a zero, ou seja, não haveria mais diferença entre valores máximo e mínimo em 2028. Como estamos em 2019, ainda faltariam nove anos para que a diferença deixasse de existir, indicand o o fator redistributivo do Fundeb. 


\section{Gráfico 5 - Diferença percentual de valores máximos e mínimos - ensino fundamental - séries iniciais urbanas (corrigidos para dez 2018)}

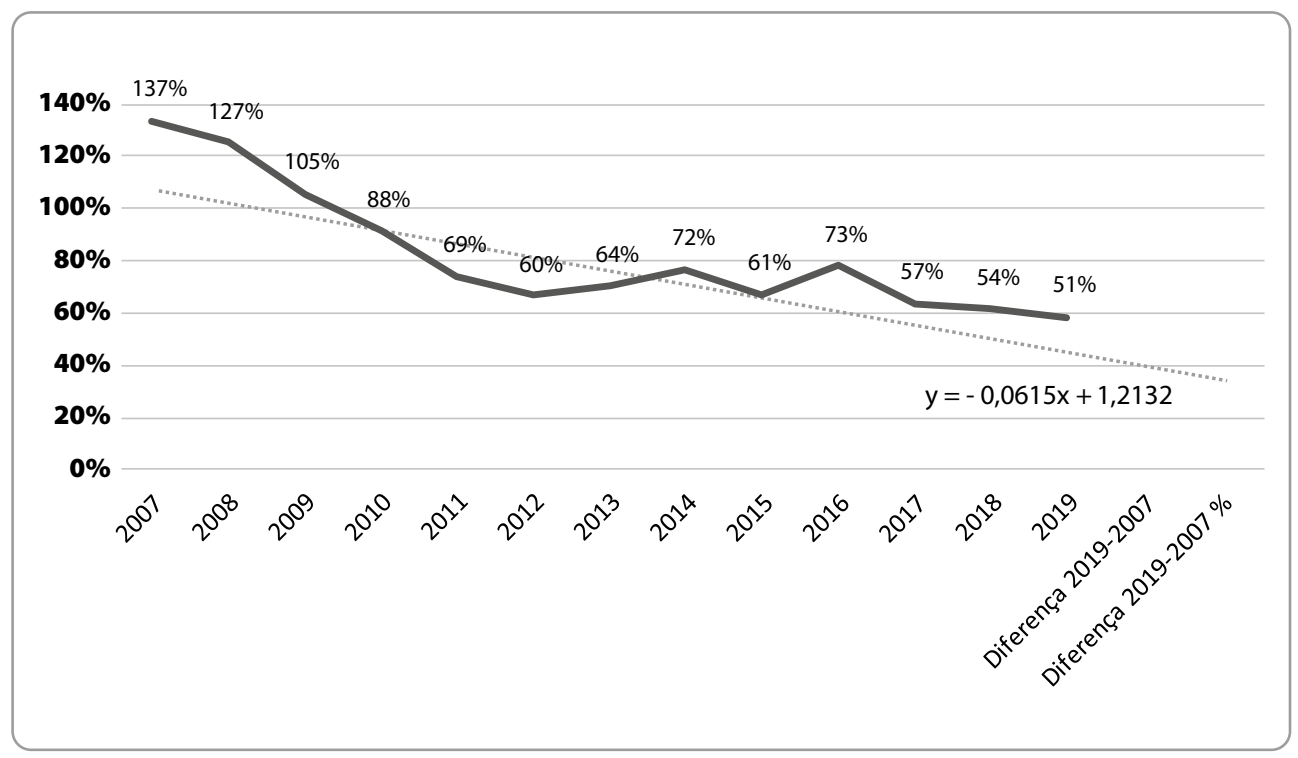

Fonte: Autores, com base nos dados do FNDE.

Da mesma forma que para as creches, a análise das diferenças percentuais dos valores máximos e mínimos para os anos iniciais do ensino fundamental urbano, apresentadas no gráfico 5, permite identificar que a maior diferença ocorreu em 2007, com 137\%, e a menor ocorreu em 2019, com 51\%, com algumas oscilações no período.

Da mesma forma, no gráfico 5 foi traçada uma linha de tendência como uma reta com a equação:

$$
y=-0,0615 x+1,2132
$$

Isso significa que a diferença será zerada, mantidas as mesmas condições (tomando como base 2007) em 19,7 anos, isto é, a diferença deixaria de existir em 2026, demonstrando seu caráter redistributivo no longo prazo.

\section{Valores mínimos e máximos do Fundeb e o Valor do CAQi}

O conceito de Custo Aluno-Qualidade (CAQ) e o de Custo Aluno-Qualidade Inicial (CAQi) foram construídos pela Campanha Nacional pelo Direito à Educação (CNDE) em 2005, com base na perspectiva constitucional de que, no País, a educação deveria ser oferecida segundo um "padrão de qualidade" (Art. 206, VII e Art. 211, §1º.). Tais conceitos incorporam nos cálculos os insumos necessários para a oferta de um ensino com qualidade, levando em consideração muitas variáveis² (alunos por sala, salários médios, tempo 
de atendimento, localização da escola, equipamentos e materiais pedagógicos, recursos financeiros para a escola etc.). Os conceitos também foram incorporados ao Parecer 08/2010 CNE/CEB³ da Câmara de Educação Básica do Conselho Nacional de Educação (CNE) em 2010, com base na mesma metodologia, e estabelecidos com relação a percentual do PIB per capita, de modo a poder ser calculado de modo claro e imediato.

Neste artigo, embora os primeiros valores do CAQi tenham sido estabelecidos antes da vigência do Fundeb, em 2005, selecionamos os valores do CAQi de 2010 e os de 2018 e os comparamos com os valores mínimos e máximos do Fundeb nos mesmos anos.

A tabela 3 revela os Valores Aluno-Ano do Fundeb mínimos nacionais para os anos de 2010 e 2018, bem como os Valores Aluno-Ano do Fundeb máximos encontrados em alguns estados nos respectivos anos. Ao mesmo tempo, apresenta os valores do Custo Aluno-Qualidade Inicial calculados pela Campanha Nacional pelo Direito à Educação nos anos de 2010 e 2018. Os valores do CAQi de 2010 foram feitos com base nos percentuais do PIB per capita de 2010, conforme o Parecer 08/2010 do CNE/CEB, e inseriu-se mais uma linha com valores corrigidos pelo INPC para dezembro de 2018. Para 2018, há dois valores do CAQi: o CAQi A, onde foram feitas atualizações nos valores dos insumos no próprio ano e determinando novos valores para o CAQi 2018; o CAQi B, que foi feito para o ano de 2018 com base nos percentuais do PIB per capita de 2016, segundo o Parecer 08/2010 CNE/CEB.

\section{Tabela 3 - Valores aluno ano Fundeb mínimos nacionais e máximos (de estados) e os valores do Custo Aluno-Qualidade Inicial (CAQi) 2010 e 2018. Valores corrigidos pelo INPC em R\$, dez 2018}

\begin{tabular}{|c|c|c|c|c|c|}
\hline Anos & $\begin{array}{l}\text { CRECHE } \\
\text { INTEGRAL } \\
\text { (em R\$) }\end{array}$ & $\begin{array}{l}\text { PRÉ } \\
\text { ESCOLA } \\
\text { PARCIAL } \\
\text { (em R\$) }\end{array}$ & $\begin{array}{l}\text { Ensino } \\
\text { Fundamental } \\
\text { Urbano Séries } \\
\text { Iniciais (em R\$) }\end{array}$ & $\begin{array}{l}\text { Ensino } \\
\text { Fundamental } \\
\text { Urbano Séries } \\
\text { Finais (em R\$) }\end{array}$ & $\begin{array}{l}\text { Ensino } \\
\text { Médio } \\
\text { Urbano } \\
\text { (em R\$) }\end{array}$ \\
\hline $\begin{array}{l}\text { Valor Aluno Ano } \\
\text { FUNDEB Mínimo } \\
\text { Nacional } 2010\end{array}$ & $2.476,42$ & $2.251,30$ & $2.251,30$ & $2.476,42$ & $2.701,56$ \\
\hline 2010 CAQi & $7.480,00$ & $2.930,00$ & $2.772,00$ & $2.727,00$ & $2.805,00$ \\
\hline $\begin{array}{l}2010 \text { CAQi } \\
\text { corrigido } 2018\end{array}$ & $11.902,12$ & $4.662,20$ & $4.410,79$ & $4.339,18$ & $4.463,30$ \\
\hline $\begin{array}{l}\text { Valor Aluno Ano } \\
\text { FUNDEB Máximo } \\
\text { (de Estado) } 2010\end{array}$ & $4.664,53$ & $4.240,48$ & $4.240,48$ & $4.664,53$ & $5.088,59$ \\
\hline $\begin{array}{l}\text { Valor Aluno Ano } \\
\text { FUNDEB Mínimo } \\
\text { Nacional } 2018\end{array}$ & $3.963,35$ & $3.048,73$ & $3.048,73$ & $3.353,60$ & $3.810,91$ \\
\hline 2018 CAQi A & $23.579,62$ & $9.607,02$ & $7.545,06$ & $6.604,99$ & $5.454,74$ \\
\hline
\end{tabular}




\begin{tabular}{l|l|l|l|l|l}
\hline Anos & $\begin{array}{l}\text { CRECHE } \\
\text { INTEGRAL } \\
\text { (em R\$) }\end{array}$ & $\begin{array}{l}\text { PRÉ } \\
\text { ESCOLA } \\
\text { PARCIAL } \\
\text { (em R\$) }\end{array}$ & $\begin{array}{l}\text { Ensino } \\
\text { Fundamental } \\
\text { Urbano Séries } \\
\text { Iniciais (em R\$) }\end{array}$ & $\begin{array}{l}\text { Ensino } \\
\text { Fundamental } \\
\text { Urbano Séries } \\
\text { Finais (em R\$) }\end{array}$ & $\begin{array}{l}\text { Ensino } \\
\text { Médio } \\
\text { Urbano } \\
\text { (em R\$) }\end{array}$ \\
\hline 2018 CAQi B & $11.858,73$ & $4.591,46$ & $4.378,61$ & 4287,39 & $4.409,02$ \\
\hline $\begin{array}{l}\text { Valor Aluno Ano } \\
\text { FUNDEB Máximo } \\
\text { (de Estado) 2018 }\end{array}$ & $6.119,39$ & $4.707,22$ & $4.707,22$ & $5.177,94$ & $5.884,03$ \\
\hline
\end{tabular}

Fonte: Autores, com base em Portarias do FNDE de 2010 e 2018. Dados da Campanha Nacional pelo Direito à Educação

Ao analisarmos os dados da tabela 3, é possível perceber que, obviamente, todos os valores dos CAQi 2010 e CAQi 2018 são superiores aos valores do VAA Fundeb mínimos nacionais nos dois anos: 2010 e 2018.

Os valores dos CAQis relativos às creches são sempre muito superiores aos valores máximos de creche do Fundeb, tanto em 2010 quanto em 2018, indicando que os fatores de ponderação criados pelo Fundeb (e acompanhados anualmente) estão claramente defasados com os reais custos de manutenção de creches públicas no País.

Com reOs CAQis em 2010 para todas as etapas e atendimentos, depois de feitas as correções da inflação pelo INPC para dez 2018, indicam que os valores do CAQi e o VAA Max Fundeb se aproximam. Na pré-escola e nas séries iniciais do ensino fundamental, o CAQié superior $\mathrm{R} \$ 4.662,20$ e $\mathrm{R} \$ 4.4410,79$ versus $\mathrm{R} \$ 4.240,48$, respectivamente. Já nas séries finais do ensino fundamental (com $\mathrm{R} \$ 4.339,18$ ) e no ensino médio (com R\$ 4.463,30), os VAA Max do Fundeb são superiores, com R\$ 4.664,53 e R\$ 5.088,59, respectivamente.

Ao verificarmos os dados do CAQi 2018A, os quais foram obtidos com as novas correções nos valores dos insumos no CAQi, eles se revelam superiores ao VAA Fundeb Max, com exceção do ensino médio. Neste caso, os valores são: do CAQi 2018A igual a R\$ 5.454,74 e o VAA Fundeb Max igual a R \$ 5.884,03. No entanto, no mesmo ano de 2018, quando o valor do CAQi 2018B é calculado com base nos percentuais (conforme o Parecer 08/2010 CNE/CEB) do PIB per capita de 2016 sempre os valores máximos do VAA Fundeb são superiores, com exceção da creche: o CAQi 2018B para a pré-escola é R\$ 4.591,46, enquanto o VAA Fundeb Max 2018 é R\$ 4.707,22. O mesmo para as séries iniciais do ensino fundamental, enquanto o CAQi 2018B para as mesmas é R\$ 4.378,61. Para as séries finais do ensino fundamental, o CAQi 2018B é R \$4.287,39 e o VAA Fundeb Max é R\$5.177,94; finalmente, no ensino médio o CAQi 2018B é R \$4.409,02, enquanto o VAA Fundeb 2018 Max é R\$5.884,03.

Tais valores indicam que com maior complementação da União, de forma a elevar os valores mínimos do VAA Fundeb, os valores do CAQi se tornariam possíveis de ser alcançados, uma vez que há certa proximidade entre os valores máximos (em alguns poucos estados) com os valores do CAQi. Levando em consideração o caráter redistributivo do 
Fundeb internamente aos estados, mas também entre os estados, é possível vislumbrar a implantação do CAQi e sua destinação à escola pública, desde que se tenha vontade política e como valor a educação de qualidade, laica e democrática para todos os brasileiros.

\section{Conclusão}

Num momento em que o Fundeb tem o seu prazo de existência - definido constitucionalmente - se esgotando em 2020, é necessário realizar análises e avaliações sobre ele.

$\mathrm{O}$ artigo se propôs a verificar o que aconteceu com os montantes do Fundeb de estados e municípios (quando somados todos os fundos do País, com as contribuições exclusivas dos entes federativos estaduais e municipais), bem como os valores das complementações da União, e ainda o que se denominou aqui de Fundeb Brasil [quando se soma os dois montantes anteriores]). Neste sentido, percebe-se que, em geral, os valores foram crescentes no período, com algumas oscilações. Identificou-se que o valor (corrigido pelo INPC para dezembro de 2018) da complementação da União partiu de um valor de $\mathrm{R}$ \$3,8 bilhões em 2007 e atingiu R $\$ 14,4$ bilhões em 2019. A somatória dos montantes dos Fundeb estados e municípios partiu de R \$ 86,8 bilhões, em 2007, em curva fortemente ascendente até 2013 (R\$ 143,5 bilhões), diminuindo e se estabilizando nos anos seguintes, e, ao retomar leve crescimento a partir de 2016, atingiu R \$ 143,5 bilhões em 2019. O Fundeb Brasil apresentou o mesmo comportamento, apenas partindo de R\$ 90,6 bilhões em 2007, atingindo R $\$ 156,4$ bilhões em 2013, diminuindo nos anos posteriores e atingindo $\mathrm{R} \$ 156,4$ bilhões em 2019.

O artigo ainda investigou o comportamento dos valores mínimos e máximos nacionais do valor aluno-ano do Fundeb de diferentes etapas e modalidades. Detectou que, embora ainda se tenha diferenças entre esses valores, há em longo prazo (em média, 20 anos a partir de sua implantação) uma tendência de diminuição dessas diferenças e sua extinção, mantidas as condições até agora detectadas, até 2028.

Com relação ao CAQi, foi percebido que, em relação aos valores explorados por aqui dos valores mínimos do VAA Fundeb nos anos de 2010 e 2018, aqueles sempre foram obviamente superiores, mas, em relação aos máximos do VAA Fundeb obtidos em alguns estados, os valores se aproximaram, especialmente quando utilizados os valores obtidos com os percentuais do PIB per capita, como previsto no Parecer $n^{\circ}$ 08/2010 do $\mathrm{CNE} / \mathrm{CEB}$, indicando que, com um maior esforço da União, esses valores poderiam ser alcançados, caso houvesse vontade política e o interesse em promover uma educação de qualidade para todos no País. 


\section{Notas}

1 O Fundo constituído em cada estado é composto, a partir de 2010, por 20\% do Imposto sobre Circulação de Mercadorias e Serviços (ICMS), Fundo de Participação dos Estados (FPE), Imposto sobre Propriedade de Veículos Automotores (IPVA), Imposto sobre a Transmissão de Bens por Causa Mortis ou Doações (ITCMD), Fundo de Participação dos Municípios (FPM), Imposto sobre a Propriedade Territorial Rural (ITR) e a compensação financeira do ICMS (Lei Kandir 87/97). A União entra com $10 \%$ do valor da somatória dos fundos dos 27 estados do país, estabelecendo um valor aluno ano mínimo nacional a ser contemplado nos estados que não o atingiram.

2 A Campanha Nacional pelo Direito à Educação realiza periodicamente a revisão dos cálculos do CAQi e do CAQ. Para melhor aferição do cálculo ver: Carreira, Denise e Pinto, José Marcelino (2005); “Educação pública de qualidade: quanto custa esse direito" (2011);

3 É importante destacar que o parecer foi reexaminado pelo Parecer 03/2019 CNE/CEB, no dia 26/3/2019, mas ainda não homologado pelo MEC.

\section{Referências}

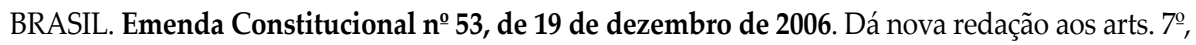
23, 30, 206, 208, 211 e 212 da Constituição Federal e ao art. 60 do Ato das Disposições Constitucionais Transitórias. Brasília, DF, 2006. Disponível em: <http://www.planalto.gov.br/ccivil_03/constituicao/ emendas/emc/emc53.htm>. Acesso em 14 maio 2019.

Lei n⿳0 11.494, de 20 de junho de 2007. Regulamenta o Fundo de Manutenção e Desenvolvimento da Educação Básica e de Valorização dos Profissionais da Educação - FUNDEB, de que trata o art. 60 do Ato das Disposições Constitucionais Transitórias; altera a Lei $\mathrm{n}^{\circ}$ 10.195, de 14 de fevereiro de 2001; revoga dispositivos das Leis $n^{\text {os }}$ 9.424, de 24 de dezembro de 1996, 10.880, de 9 de junho de 2004, e 10.845, de 5 de março de 2004; e dá outras providências. Brasília, DF, 2007a. Disponível em: <http://www.planalto.gov.br/ccivil_03/_ato2007-2010/2007/Lei/L11494.htm>. Acesso em 14 maio 2019.

Portaria Interministerial no 1030 , de 6 de novembro de 2007. Define e divulga os parâmetros anuais de operacionalização do Fundeb para o exercício de 2007; atualiza e divulga o valor da complementação da União ao Fundeb em 2007. Brasília, DF, 2007b.

Disponível em: <https://www.fnde.gov.br/acesso-a-informacao/institucional/legislacao/item/3601portaria-interministerial-n\%C2\%BA-1030-de-6-de-novembro-de-2007>. Acesso em 14 maio 2019.

Decreto no 6.253, de 13 de novembro de 2007. Dispõe sobre o Fundo de Manutenção e Desenvolvimento da Educação Básica e de Valorização dos Profissionais da Educação - FUNDEB, regulamenta a Lei n ${ }^{\circ} 11.494$, de 20 de junho de 2007, e dá outras providências. Brasília, DF, 2007c. Disponível em: <http://www.planalto.gov.br/ccivil_03/_Ato2007-2010/2007/Decreto/D6253.htm>. Acesso em 14 maio 2019.

Portaria Interministerial n⿳0 1.027, de 19 de agosto de 2008. Define e divulga os parâmetros anuais de operacionalização do Fundeb para o exercício de 2008 e revoga a Portaria Interministerial n⿳o 598, de 19/05/2008.Brasilia, DF, 2008. Disponível em: <https:/www.fnde.gov.br/acesso-a-informacao/ institucional/legislacao/item/3600-portaria-interministerial-n\%C2\%BA-1027-de-19-de-agosto-de-2008>. Acesso em 14 maio 2019. 
Portaria MEC no 788, de 14 de agosto de 2009. Redefine e divulga os parâmetros anuais de operacionalização do Fundeb para o exercício de 2009. Brasília, DF, 2009. Disponível em: <https://www. fnde.gov.br/acesso-a-informacao/institucional/legislacao/item/3576-portaria-mec-n\%C2\%BA-788-de-14de-agosto-de-2009>. Acesso em 14 maio 2019.

. Portaria Interministerial no 538-A, de 26 de Abril de 2010. Retifica e divulga os parâmetros anuais de operacionalização do Fundeb para o exercício de 2010.Brasília, DF, 2010. Disponível em: <https://www.fnde.gov.br/acesso-a-informacao/institucional/legislacao/item/3581-portariainterministerial-n\%C2\%BA-538-a-de-26-de-abril-de-2010>. Acesso em 14 maio 2019.

Portaria Interministerial no 1721 , de 7 de novembro de 2011. Retificação da Portaria Interministerial MEC/MF nº 477, de 28 de abril de 2011 e operacionalização do FUNDEB no exercício de 2011. Brasília, DF, 2011. Disponível em: <https://www.fnde.gov.br/acesso-a-informacao/institucional/ legislacao/item/3599-portaria-interministerial-n\%C2\%BA-1721-de-7-de-novembro-de-2011>. Acesso em 14 maio 2019.

. Portaria Interministerial n⿳0 $\mathbf{0}$ 1.495, de 28 de dezembro de 2012. Redefine e divulga os parâmetros anuais de operacionalização do Fundeb para o exercício de 2012.Brasília, DF, 2012. Disponível em: <https://www.fnde.gov.br/acesso-a-informacao/institucional/legislacao/item/4012portaria-interministerial-n\%C2\%BA-1-495,-de-28-de-dezembro-de-2012>. Acesso em 14 maio 2019.

. Portaria Interministerial no 4, de 7 de maio de 2013(*).Altera a Portaria Interministerial MEC/ MF n 1.496, de 28 de dezembro de 2012. Define e divulga os parâmetros anuais de operacionalização do Fundeb para o exercício de 2013.Brasília, DF, 2013a. Disponível em: <https://www.fnde.gov.br/acessoa-informacao/institucional/legislacao/item/4501-portaria-interministerial-n\%C2\%BA-4,-de-7-de-maiode-2013>. Acesso em 14 maio 2019.

Portaria Interministerial no 19, de 27 de dezembro de 2013. Define e divulga os parâmetros anuais de operacionalização do Fundeb para o exercício de 2014.Brasília, DF, 2013b. Disponível em: <https://www.fnde.gov.br/acesso-a-informacao/institucional/legislacao/item/5147-portariainterministerial-n\%C2\%BA-19,-de-27-de-dezembro-de-2013>. Acesso em 14 maio 2019.

Portaria Interministerial $\mathbf{n}^{\mathbf{0}}$ - 8, de 5 de novembro de 2015. Dispõe sobre o valor anual mínimo nacional por aluno, na forma prevista no art. $4^{\circ}, \S \S 1^{\circ}$ e $2^{\circ}$, e no art. 15, inciso IV, da Lei $n^{\circ} 11.494$, de 2007, fica definido em $\mathrm{R} \$ 2.545,31$ (dois mil, quinhentos e quarenta e cinco reais e trinta e um centavos), para o exercício de 2015.Brasília, DF, 2015. Disponível em: <https://www.fnde.gov.br/acesso-a-informacao/ institucional/legislacao/item/7698-portaria-interministerial-mec-mf-n\%C2\%BA-8,-de-5-de-novembrode-2015>. Acesso em 14 maio 2019.

Portaria Interministerial n⿳0 7, de 16 de dezembro de 2016. Brasília, DF, 2016. Disponível em: $<$ http://www.in.gov.br/materia/-/asset_publisher/Kujrw0TZC2Mb/content/id/22192870/do1-2016-12-19portaria-interministerial-n-7-de-16-de-dezembro-de-2016-22192832>. Acesso em 14 maio 2019.

Portaria Interministerial no 8, de 29 de novembro de 2017. Altera a Portaria Interministerial MEC/MF nº 8, de 26 de dezembro de 2016, que estabelece os parâmetros operacionais para o Fundo de Manutenção e Desenvolvimento da Educação Básica e de Valorização dos Profissionais da Educação - Fundeb, no exercício de 2017, e dá outras providências. Brasília, DF, 2017. Disponível em: <http:// www.in.gov.br/materia/-/asset_publisher/Kujrw0TZC2Mb/content/id/577281/do1-2017-11-30-portariainterministerial-n-8-de-29-de-novembro-de-2017-577277>. Acesso em 14 maio 2019.

.Portaria Interministerial no 06, de 26 de dezembro de 2018. Altera a Portaria Interministerial $\overline{\mathrm{MEC} / \mathrm{MF}} \mathrm{n}^{\mathrm{o}}$ 10, de 28 de dezembro de 2017.Brasília, DF, 2018a. Disponível em: <https://www.fnde.gov. br/acesso-a-informacao/institucional/legislacao/item/12363-portaria-interministerial-mec-mf-n-6-de-26de-dezembro-de-2018>. Acesso em 14 maio 2019. 
Portaria interministerial $\mathrm{n}^{\mathrm{0}}$ 7, de 28 de dezembro de 2018. Estabelece os parâmetros operacionais para o Fundo de Manutenção e Desenvolvimento da Educação Básica e de Valorização dos Profissionais da Educação - FUNDEB, no exercício de 2019.Brasília, DF, 2018b. Disponível em: <https:// www.fnde.gov.br/acesso-a-informacao/institucional/legislacao/item/12386-portaria-interministerial-mecmf-n-7-de-28-de-dezembro-de-2018>. Acesso em 14 maio 2019.

Campanha Nacional pelo Direito à Educação. CAQi e CAQ no PNE: quanto custa a educação pública de qualidade no Brasil? São Paulo : Campanha Nacional pelo Direito à Educação, 2018. Encontrado em http://www.custoalunoqualidade.org.br/pdf/quanto-custa-a-educacao-publica-de-qualidadeno-brasil.pdf acesso em 29/06/2019.

Campanha Nacional pelo Direito à Educação. Educação pública de qualidade: quanto custa esse direito? São Paulo : Campanha Nacional pelo Direito à Educação. 2a Edição, 2011. Encontrado em http://campanha.org.br/wp-content/uploads/2016/02/CAQieducativo_2Edicao.pdf, acesso em 28/6/2019.

INSTITUTO NACIONAL DE ESTUDOS E PESQUISAS EDUCACIONAIS ANÍSIO TEIXEIRA. Sinopse Estatística da Educação Básica 2007. Brasília, DF, 2008. Disponível em: <http://inep.gov.br/sinopsesestatisticas-da-educacao-basica>. Acesso em: 10 jun 2019.

INSTITUTO NACIONAL DE ESTUDOS E PESQUISAS EDUCACIONAIS ANÍSIO TEIXEIRA. Sinopse Estatística da Educação Básica 2018. Brasília, DF, 2019. Disponível em: <http://inep.gov.br/sinopsesestatisticas-da-educacao-basica>. Acesso em: 10 junho 2019. 